\title{
Verbal R-S strength following S-R extinction'
}

\author{
John P. Houston \\ UNIVERSITY OF CALIFORNLA, BERKELEY
}

\begin{abstract}
Retroactive inhibition (RI) of R-S associations was investigated by comparing $\mathrm{B}-\mathrm{A}$ recall following $\mathrm{A}-\mathrm{B}$, A-C learning with $\mathrm{B}-\mathrm{A}$ recall following $\mathrm{A}-\mathrm{B}$ learning and an interpolated rest activity. Highly integrated and available sequences of $\mathrm{A}$ units were employed to avoid greater A unit availability in the experimental group at the time of recall. The results indicated significant RI of $\mathrm{R}-\mathrm{S}$ associations following A-B, A-C learning.

\section{Problem}

One of the issues in the study of verbal R-S, or backward, associations has been the problem of the extent to which R-S learning is dependent upon S-R learning. The evidence now clearly indicates that acquisition of $\mathrm{R}-\mathrm{S}$ associations is, under certain circumstances, a direct function of the formation of S-R associations (Richardson, 1960). On the other hand, R-S unlearning or extinction has not been shown to vary with S-R unlearning. Keppel and Underwood (1962), in a study of $\mathrm{RI}$ of R-S associations, compared B-A retention following $\mathrm{A}-\mathrm{B}, \mathrm{A}-\mathrm{C}$ learning with $\mathrm{B}-\mathrm{A}$ retention following $\mathrm{A}-\mathrm{B}$ learning and an interpolated activity. $\mathrm{B}-\mathrm{A}$ retention in the two conditions did not differ. On the basis of these data the authors tentatively conclude that extinction of forward A-B associations, which has been shown to occur in the A-B, A-C situation (Barnes \& Underwood, 1959), does not affect the strength of backward B-A associations. However, they also suggest that the lack of significant difference between the experimental and control groups could have been due to a procedural artifact. The experimental group was exposed to the A units during A-C learning while the control group engaged in the unrelated rest activity. This increased experience with the A units may have led to a greater degree of firstlist stimulus availability on the part of the experimental group at the time of recall. Thus, any superiority of the experimental group in terms of B-A associations could have been masked by the increased probability of the experimental Ss guessing correctly. This is particularly likely in the light of the fact that the stimulus units were nonsense syllables and, therefore, apt to require considerable integration. The present experiment was designed to test the effect of $\mathrm{S}-\mathrm{R}$ extinction on $\mathrm{R}-\mathrm{S}$ strength in the A-B, A-C situation when stimulus availability differences between the experimental and control groups were minimized through the use of highly available, highly integrated sequences of stimulus units. Method

The Ss were 30 University of California students whose participation was in fulfillment of a course requirement. The majority of the Ss had participated in prior paired- associate learning experiments but none had engaged in $\mathrm{R}-\mathrm{S}$ recall. The $\mathrm{A}-\mathrm{B}$ and $\mathrm{A}-\mathrm{C}$ lists were each composed of 12 number-adjective pairs. The stimuli were the words 1 through 12 . The responses were two sets of 12 common adjectives having little interlist and intralist similarity. Eight of the 12 adjectives in each list were those employed by Keppel and Underwood (1962). The remaining adjectives, chosen from the Thorndike and Lorge (1944) word count, were comparable in terms of frequency of occurrence. Three presentation orders of each list were developed to minimize serial learning. Each order served equally frequently as the starting order. The Ss were assigned alternately to the Experimental and Control conditions as they appeared in the laboratory. Both the Control and Experimental Ss learned the A-B list to a criterion of 3 out of 12 correct responses. Following a $30-\mathrm{sec}$. rest interval the Experimental Ss were presented the A-C list for 10 trials. All learning was at a $2: 2-\mathrm{sec}$. rate of presentation with a 4-sec. intertrial interval on a Stowe memory drum. The Control Ss were given a corresponding 30sec. rest interval and then engaged in $61 / 2 \mathrm{~min}$. (the time required by the Experimental Ss to learn the A-C list) of a letter cancellation task. Fifteen sec. after the elapse of the A-C list time period bothgroups were given a 2-min. B-A free recall test. Ss were required to write the first-list stimuli next to the first-list responses which were dittoed on a sheet of paper. The order of the first-list responses on the sheet corresponded to the order of the items S would have received had he had another first-list learning trial. All Ss were encouraged to guess.

\section{Results and Diseussion}

The mean numbers of trials to a criterion of one perfect trial on the first list were 1.80 and 2.13 for the Control and Experimental groups, respectively. The difference between these means was not significant, $\mathrm{t}<1.0$, indicating that the groups were comparable in terms of learning ability. Because all Ss in both conditions used all 12 numbers in the recall test it may be assumed that the groups did not differ in terms of the number of correctly guessed responses.

The mean numbers of first-list stimuli paired with the correct first-list responses were $7.67, \mathrm{SD}=2.91$, for the Experimental and 10.87, $\mathrm{SD}=1.52$, for the Control group. Because the distribution of the Control data was extremely skewed, with 8 of the 15 Ss recalling all 12 stimuli correctly, the data were evaluated in terms of a median test, $x^{2}=6.81, \mathrm{P}<.01$. Thus the Experimental group displayed significant RI of R-S associations when compared with the Control condition. This result, taken 
together with previous findings, suggests that both acquisition and extinction of forward associations are correlated with corresponding increases and decreases in the strength of R-S associations.

It should be noted that the difference between the Experimental and the Control conditions could well have been underestimated due to the obvious ceiling effect in the case of the control condition. With materials and procedures which resulted in less overall $\mathrm{R}-\mathrm{S}$ retention the RI effect might be magnified.

\section{References}

BARNES, J. M., \& UNDERWOOD, B. J. "Fate" of firstlist associations in transfer theory. J.exp. Psychol.,

\section{Abstract}

MARTIN, R. CHRIS (U. Florida), \& MELVIN, KENNETH B. (U. Alabama). Fear responses of Bobwhite Quail (Colinus virginianus) to a model and a live Redtailed Hawk (Buteo jamaicensis). Psychol. Forsch., in press.-Two groups of 9 quail each were presented either with a live Red-tailed Hawk or a life-sized silhouette of it. The Ss were tested individually twice a day for at least 5 days in a pen over which the stimuli were "flown." After S's performance became stable, the other stimulus was presented for a second series of
$1959,58,97-105$.

KEPPEL, G., \& UNDERWOOD, B. J. Retroactive inhibition of R-S associations. J.exp. Psychol., 1962, 64, 400-404.

RICHARDSON, J. Comparison of S-R and R-S learning of paired-associates. Psychol. Rep., 1960, 7, 225-228.

THORNDIKE, E. L., \& LORGE, I. The teacher's word book of 30,000 words. New York: Bureau of Publications, Teachers College, Columbia Univer., 1944. Note

1. This study was conducted during the tenure of the author's USPHS postdoctoral fellowship at the Institute of Human Learning, University of California, Berkeley. trials. Responses to the model were only $5 \%$ of the duration (sec.) of responses to the hawk. Habituation occurred reliably with repeated presentations of both stimuli, and while the number of fear responses decreased, an increase occurred in orienting responses. A trend for prior habituation to the model to lead to faster habituation to the hawk was noted. It was concluded that the releasing value of such a model is relatively low, and that this might serve as a partial explanation for the controversy over the "short-neck" as a sign-stimulus. 